\title{
FROM LEARNER TO THERAPIST: A STORY OF TRANSCENDENCE AND TRANSFORMATION
}

\author{
Hester G Pretorius \\ D Litt et Phil (Psychology) \\ Deputy Chairperson, Department of Psychology, University of Johannesburg \\ Corresponding author: hgpr@rau.ac.za
}

\section{Anne-Marie Lydall \\ MA Psychology student}

\section{Rahima Mohamed-Patel}

MA Psychology student

\section{Antoinette Rikhotso}

MA Psychology student

\section{Grant W Evans}

MA Psychology student

Keywords: Gestalt; training; intersubjectivity; presentness; experiential; therapist

\begin{abstract}
Therapeutic interventions are guided as much by a therapist's philosophy as they are by an understanding of psychological and therapeutic principles. An individual gravitates toward specific philosophical assumptions largely because they resonate with personal, subjective themes in this person's life. This paper explores according to the phenonemenological approach of the training of a group of four trainee Gestalt therapists from four different traditions in the context of a culturally and racially diverse South Africa in the opening years of the third millennium. The intention of the authors was to focus specifically on their lived experience with a view to observing how the different historically situated contexts have influenced the incremental shift in the acquisition of the skills of the Gestalt therapist. It is the authors' contention that Gestalt therapeutic training needs to transcend the Western and Eurocentric traditions in which it is historically sited in order to become relevant to the multi-ethnic and multi-cultural realities of the global village characterised as it is by diversity. As such the benefits of Gestalt therapy, as experienced by the group, have implications that are broadly applicable.
\end{abstract}

\section{OPSOMMING}

Terapeutiese intervensies word net soveel gerig deur ' $n$ terapeut se lewensfilosofie, as deur 'n begrip van sielkundige en terapeutiese beginsels. ' $n$ Individu is geneig om na sekere filosofiese veronderstellings aan te hang, hoofsaaklik omdat hulle aanklank vind by persoonlike, subjektiewe temas in die persoon se lewe. Hierdie artikel ondersoek volgens die fenomenologiese benadering die opleiding van 'n groep van vier leerling Gestaltterapeute uit vier verskillende tradisies binne die konteks van ' $n$ kultureel en rasse-diverse Suid-Afrika in die beginjare van die derde millenium. Die skrywers het beoog om spesifiek op hulle beleefde ervaring te fokus. Die doel daarvan was om waar te neem hoe die verskeie histories gesitueerde kontekste, die toenemende verskuiwing in die verwerving van die vaardighede van die Gestalt-terapeut beinvloed het. Die skrywers is van mening dat Gestalt terapeutiese opleiding die Westerse en Eurosentriese tradisies, waarin dit histories gesitueerd is, behoort te transendeer, om sodoende toepaslik te kan wees in die multi-etniese en multi kulturele werklikheid van die "global village", soos wat dit deur 
diversiteit gekenmerk word. As sulks, het die voordele van Gestalt-terapie, soos wat dit deur die groep ondervind is, implikasies wat op ' $n$ wye spectrum van toepassing is.

\section{INTRODUCTION}

Therapeutic interventions are guided as much by a therapist's philosophy as they are by an understanding of psychological and therapeutic principles. An individual gravitates toward specific philosophical assumptions largely because they resonate with personal, subjective themes in this person's life. Everything one understands and believes about the human condition and every assumption one makes about human nature is essentially a reflection of the historical, cultural and political forces that govern one's ways of seeing and being in the world (Bankart, 1997:5). It is the intention of the authors to focus specifically on their experiences of Gestalt therapy as trainee therapists, and to identify those elements of Gestalt therapy that have resonated most strongly with personal themes.

\section{HISTORICAL OVERVIEW}

It is beyond the scope of this article to adequately explore the forces that shaped the development of Gestalt therapy. A brief glimpse into some of the elements that may have been influential to Perls as the founder of Gestalt Therapy initially reveals a psychoanalyst who studied in Berlin during the peak of psychoanalytic thinking. Influences include Adler, Jung and Freud, whom he met (Bankart, 1997:316). Psychoanalytic ideas that proved influential include the idea of projection and the significance of transference (Perls, Hefferline \& Goodman, 1951:254; Perls, 1969:35). Klein's idea of polarities (for example, love-hate) that co-exist in humans, Rank's perception of the dream being the projection of the dreamer as well as Horney's emphasis on the cultural medium, the importance of the present and Winnicott's reduction of the relevance of interpretation were also influential (Sinay, 1997:37).

Perls escaped Nazi Germany by moving to South Africa where he remained for 12 years before moving to New York where he formed the famous Group of Seven in 1950 (Sinay, 1997:17). The members of the group comprised of European immigrants whose valuable knowledge and talents contributed to the development of Gestalt Therapy. His wife, Laura, was also instru- mental in including many Gestalt psychology and existential-phenomenological principles into Gestalt therapy including the idea of the foreground and background of perception and experience and the concept of incomplete gestalts. This concept is also related to the emphasis placed on dialogue in the therapeutic relationship (Buber, 1970:62).

The existentialists' emphasis on awareness is as significant as is the importance of meaning creation and the view of human nature as open-minded, flexible and capable of an enormous range of experiences. The phenomenology's focus on the description of the experience rather than on its explanation is a core principle of Gestalt Therapy, as is the premise that perception of the immediate experience is essential and the premise that the process that is occurring in the here-and-now (Sinay, 1997:35).

Perls adopted the idea of the Yin and Yang from the Zen philosophy (Sinay, 1997:37). According to Perls (1969:18), personality contains polar tendencies and the tensions caused by conflicting polarities are the essence of living. Change begins through the acceptance of these polarities. The emphasis on spontaneity is reflected in the therapeutic process through using natural behaviour and expressions that emerge (Sinay, 1997:37). In addition, Taoism's view of the body as the seat of the spirit was of significance.

It is apparent that the various influences of Gestalt therapy resonate with each other in terms of their fundamental principles so that "Gestalt therapy is a philosophy that tries to be in harmony, in alignment with everything else, with medicine, with science and with the universe" (Perls, 1969:16). Perls achieved the integrative goal of Gestalt therapy by producing a whole or gestalt from the different sources prevailing at his time. The challenge for us as trainee therapists in Gestalt is similarly to produce such a gestalt. Living in South Africa we are affected by a multitude of local and global influences: socio-political change; the HIV/AIDS epidemic; technological advances; the prevalence of poverty, unemployment and global strife. Moreover, as trainee therapists undergoing specialised training in 
Gestalt therapy, we are attempting to reinterpret the fundamental tenets of a modernistic theory in a postmodern era while accommodating the needs of contemporary culture by finding our own individual styles of engaging with this approach. The transcendent or unifying element to this divide is the meaning that each epistemology holds for its adherents as can be achieved through awareness. According to a comparative analysis by Prochaska and Norcross (1999:492), "the major psychotherapies diverge much more in terms of the content to be changed than in the processes used to change that content" so that awareness is crucial for behaviour change. At the heart of this process lies the process of meaning-making with awareness as its outcome. The focus on meaning-making emerges at this time perhaps because of existential concerns and for humanity's need to find hope and goodness in each other in an era dominated by animosity and alienation.

Therefore, this article argues that, in much the same way that Perls created a gestalt of his personal life philosophy, training and the culturally and historically determined aspects of his life in order to produce Gestalt therapy, each of the trainees underwent a process of producing a gestalt of their own unique historical, cultural and philosophical backgrounds including the different experiences of, for example, apartheid through the eyes of the Indian, the Black or the White community. Thus, for each trainee their background was significant to each one's own transformation but that beyond this, these individual gestalts came together to form a bigger communal group gestalt, perhaps in some ways mirroring the process of therapy between a therapist and a client. The implications of this are evident not only for therapy but also for training as this gestalt formation and the acknowledgement of unique gestalts coming together to form something greater can clearly be a powerful tool towards reconciliation especially in light of South Africa's recent divided past.

\section{EXPERIENCE OF THE TRAINING}

\section{Expectations}

On beginning the course we expected to be taught various techniques which could be practised until we attained competency and to exit the course equipped with a "recipe" for Gestalt therapy. We positioned our trainer as the expert and ourselves as learners depen- dent on her expertise.

\section{Context of training}

In our first meeting our expectations were confounded. We discovered that the process of learning would be co-created between trainer and learners alike. The process of learning became a live therapeutic situation, with all of us becoming client, therapist and observer in turn. We realised that training would entail a major conceptual shift from understanding Gestalt therapy as a technique, to an everyday experienced reality. Much of the training occurred between the learners in a journey of discovery and reflection. The role of the trainer was that of compassionate expert who accompanied us nonprescriptively.

\section{Lived experience of the course}

Themes common to us as members of the group can be described on three different levels: as trainee therapists observing the practice of Gestalt therapy, as clients and as practising trainee therapists.

\section{As observer}

Initially as learner-observers, we were both interested and absorbed in the process that we were witnessing. However as the learner-client entered his or her lived experience, the contemporaneous reliving of the experience by the learner/client became a common experience of all. As observers, we all experienced the power and effectiveness of entering another person's lived world. This was most profound when following dream work and the empty chair as we experienced bodily tactile, olfactory and visual sensations so that we experienced the exercise not only cognitively, but also emotionally. As a result, we became aware of how our bodies were resonating with the learner-client's experiences. Another experience common to all, was the dissolution of external reality where external sensory inputs, such as noise, were excluded from conscious awareness as we attained a trance-like state of altered awareness. As learner-observers, we also felt more in touch with the client's body language, often echoing it in the way each member of a team of cyclists will sway to one side individually yet in synchrony as they negotiate a bend in the road.

The realness and authenticity of the client's experience 
elicited an emotional response in us as observers characterised by empathy and compassion. This aroused in us a deeply respectful attitude to the clients' ability to negotiate their own lived worlds. There was wonderment at the emerging confirmation that the clients as the first citizens of their own worlds were indeed able to assume responsibility for their own healing processes. It appeared to us that the process was the expansion of awareness from one level to a metaperspective, facilitating the fashioning of new connections that results in meaning-making. It is this different meaning that the client is able to use on an ongoing basis as a fresh template for the creation of different experiences.

On a cognitive level, we felt perplexed by the way that the trainer-therapist was so attuned to the client's experience with such fitting reflections that these appeared to naturally guide the client to deeper awareness. The acquisition of such skill seemed to us an insurmountable task.

\section{As client}

Our experience as learner-clients was profound. In contrast to expectation, we experienced a degree of reality that transcended a methodology and technique. In the journey of self-discovery (as defined by Perls, Hefferline \& Goodman, 1951:27) the past became a part of the present where repressed parts of the self were brought into the present and dealt with. For example, in the empty chair demonstration one of us recalled an unresolved event from her childhood. Transcending the boundaries of time and place, she re-lived the incident and in so doing re-experienced the emotions of that time in the present. She was able to add to the experience the knowledge and awareness of the intervening years of her life thus integrating the past experience with it. This altered the past experience in a way that when it is now recalled, the past event seems different and is remembered differently. This change has persisted to the time of writing and has led to corresponding shifts of experience in her daily lived world. It is a further source of awe for us how the personal shift we all underwent in turn, has created the opportunity and space for corresponding shifts in our interaction with others who know nothing of our journey. This inspires the hopeful idea that painful past experiences can be altered in the present awareness of them and that this change transmits itself into the broader con- text. Although insight per se does not appear to elicit change, the awareness that is generated through reliving an experience have demonstrated for us, and made personally meaningful, the goals of Gestalt therapy which promote integration and the development of meaning creation.

\section{As therapist}

Initially, we had felt considerably daunted and illequipped to fulfil the expectations, of what appeared at the outset, a procedure steeped in 'magic'. However, the actual experience of being therapists confounded pre-conception. As the intersubjective space of the therapeutic relationship assumed a central locus, transcendence of contact boundaries occurred so that it is as though a bubble enveloped learner-therapist and learner-client and is what we understand to be presentness as defined by Buber (1970:64). This makes possible the deep and accurate empathy out of which emerges the intuitive ability to join the clients in their lived experience. Hence the therapist's reflections are not planned in a cognitive sense but instead emerge spontaneously as a natural consequence to being in this intersubjective space created by dialogue. Dialogue, in this sense, includes communication through speech, bodiliness, art, fantasy and other media which are used for the purpose of creating a shared intersubjective world.

\section{Meta-reflection on the process of training}

We each engaged the therapeutic interaction with our unique styles in terms framed by our own contextual subjectivity. However, the process enabled us to transcend the personal limitations of our own lived world. For example, using the empty chair it was possible to voice that which is silenced within the bounds set by familial norms or culture.

\section{Peer group educators}

When the training commenced, we began by consulting the necessary literature, which would inform the process with the relevant theoretical underpinnings The modalities of therapy such as guided imagery, dream analysis and empty chair, were demonstrated by our trainer as instances of therapy. As students, we continued to meet without her with the view to put into practise our nascent skills. However, these became not so much practice sessions, but a valuable time of 
actual therapy with a special dynamic: in the subjective therapeutic experience, there was an authentic presentness and joining between learner-client and learnertherapist, as well as with the team of learner/observers. The ' $"$ and 'you' were transformed to ' $w e$ ' as a deeper learning took place, surpassing skill acquisition.

\section{Responsibility}

It became clear to us that Gestalt therapy does not position the therapist as the expert with the client as recipient of such expertise. As learner-clients we understood how the client takes responsibility that, in a very real way, positions him as expert. The exploration of the client's lived world in a respectful and skilled dialogue, positioned both therapist and client in a way that the client took responsibility for the journey into meaning-making and emerging reality. Hence the process of Gestalt therapy constantly reinforced our sense that this responsibility remains with the clients who know their world best. This underscores the concept of existential freedom, and this is empowering and invigorating.

\section{Impact of the client experience in becom- ing a therapist}

Each trainee was privileged to be both client and therapist during training. It became clear to the group that the experience of being a client and the benefit arising therefrom, allowed the same person, when in the role of the therapist, to connect with the client in an authentic manner. It also assisted the integration of the personal and professional self so that this integration facilitated the joining with the client. In genuinely entering into the role of client and then entering into the lived experience of the client as therapist, facilitated learning that transcends learning a technique. Far from being an academic exercise, this held the realisation of redeeming potentials and indeed of salvation, for the emerging therapist.

\section{DISCUSSION}

\section{Intersubjectivity}

The concept of intersubjectivity is significant within the therapeutic process so that according to Buber (1967:140; 1970:181), the I-Thou relationship affirms one's wholeness. Buber (1970:80) maintains that authentic human existence can only occur in the I-Thou since only through the Thou, or other, can there be knowledge of the I. This suggests that the self is social, and as such, is in constant interaction and dialogue with the environment, which includes objects, other humans and God. As trainee therapists, each member of the group underwent experiential practice which was characterised by an almost complete, mutual and emotional involvement as both client and therapist in what can be termed an l-thou relationship (Buber, 1970:179; Perls, 1973:24). Perls (1969:213) notes that there is an overlap between the experience of therapist and client within this I-thou relationship that facilitates the development of understanding and awareness for both client and therapist. However, the person's lived experience and struggle to find meaning and fulfilment is individual for each person within the relationship.

According to Buber (1967:144), the therapists meets the situation as persons equipped only with the trade of their sciences and the theory of their schools. The self of the therapist which is needed to facilitate the establishment of the genuine dialogical relationship of the I-Thou is hidden under the structures erected through training. However, the therapeutic relationship is an intersubjective space that facilitates healing through dialogue (Buckley, 2003:8). Buber (1970:124) identifies the elements of inclusion, presentness, and commitment where the therapist's striving to imagine and understand the reality and life-world of the client defines the therapeutic relationship.

According to Lazar (2000:342), the therapist's role is to be present and knowing based not on objective observation, but rather on presentness as a mode of being that allows the presence of the client to resonate within the therapist so that each impacts on the other. Presentness suggests an unconscious and mysterious process of two souls connecting in an existence beyond understanding (Buber, 1967:64). This reflects the intersubjective connection between two human beings.

The focus is on the here-and-now and the goal is to establish a secure base which facilitates the exploration of the client's lived world through dialogue (Bowlby, 1988:138). The I-Thou of the therapeutic relationship reflects the distinctiveness of the therapist and client while simultaneously emphasising how they impact on one another. 


\section{Language and relatedness}

If growth and healing comes from a genuine relatedness between client and therapist then language is the medium that facilitates relatedness. Self is not an isolated, autonomous being, but rather is constructed in relationship (Gergen, 1991:6). The process of understanding requires the active and co-operative enterprise of those involved in a relationship. Buber maintained that language not only determine people's concepts of relationship and community, but can radically change their experiences of them as well (Kaufmann, 1970:56). This implies the necessity for being fully available in the interaction and language wherein both client and therapist are able to touch each other's subjective experience.

\section{Language and meaning}

Meaning cannot exist apart from linguistic content and the act of communication, and the role of language is both instrumental, and creative so that thought and meaning, come to fruition in language (Terrell \& Lyddon, 1996:32). Through language client and therapist share images and stories in an ongoing reciprocal conversation (Becvar \& Becvar, 2000:94) allowing for new meaning to emerge. Hence, language becomes the vehicle for making sense of experience functioning as scaffolding (Terrell \& Lyddon, 1996:33).

\section{Language and dialogue in Gestalt training}

In our training, language was experienced as convention, couched in symbol and metaphor, and verbally as well as non-verbally. Our dialogue as therapist, client and observer was by implication a form of speech, body language, art and fantasy that was an important and integral part of the procedure. As each participated in putting into practice what was taught, the group wove a common world of meaning and relatedness.

In one instance of guided imagery, a picture emerged for the learner-client of swimming in a sea full of sharks. It proved quite daunting and challenging to her, as indeed it did to all of. Each person was bound together in a common bond created by the threatening fantasy of predatory, circling sharks. It did not require interpretation because there existed the mutually understandable language of metaphor. Even though everybody visualised their own special and unique pictures, there was a common language of meaning, as we all experienced the power and threat of the sharks. According to Hillman, the soul is made up of images sited in fantasy and dreams, so that any attempt to seek meaning necessitates a profound inner journey in the imagination, because "we gain breadth of soul and wider horizons through vertical descent, through the inwardness of the image" (Hillman, 1976:94).

Perls (1973:180) was fascinated by dreams maintaining that the dream is the most spontaneous expression of the existence of the human being. He proposes that each aspect of the dream reflects different fragments of personality and that intrapsychic processes are projected in dreams which hold a message about the nature of one's existence. The language of the various dreams that were part of the training process, held us all in a trance-like state as we communicated visions that spoke to each of us personally.

The language of a young girl in conversation with a father in the empty chair, enabled the emergence of meaning and reality. Client, therapist and observers shared in that dialogue, in a world of relatedness and meaning. The woman who became that young girl, spoke not only an instrumental language, but a creative one as well, as her body and voice participated in the dialogue. It demanded that we, as listeners, participate in the language of meaning and relatedness that was being created and the healing that was taking place.

\section{Awareness and insight}

Polster and Polster (1973:211) distinguish between awareness and insight where insight is believed to be exclusively linked to an illumination that occurs only at a specific moment and is thus not readily available all the time. While recognising that feelings of personal experience are inevitably linked to sensation, feelings are believed to have a quality that transcends the range of physical sensations including an attempt to fit a particular event into the larger landscape of one's experience. In Gestalt Therapy, the description of feelings and the subsequent organised expression that emerges is of importance (Polster \& Polster, 1973:18). Feelings are thus used as openings into the cycle of awareness and expression (Fagan, 1972:122). 
Recent research by Damasio (2000:228) indicates that although emotions occur without consciousness, consciousness permits the subjective experience of feeling. This is an endorsement of Churchland's (1986:325) assertion that emotions release a flood of chemical messengers which create the particular environment in which all other brain function occurs, and which has been demonstrated by Pert (1997:72) in her research of neurotransmitters. Hence, emotion is at the basis of the process of meaning attribution. The chemical messengers, or hormones, triggered by emotion, result in changes to neuronal connections, as they become personalised in terms of the particular experience. Freeman (1996:69) describes how oxytocin, commonly released in experiences such as falling in love, leads to behaviour change through dissolving the patterns of connections among neurons that hold experience, so that new experiences can form. Initially this can be experienced as an anxiety-provoking loss of sense of identity, but provides the opportunity for new connections to form resulting in the bonding which characterises a relationship based in trust. This has long been recognised, from ancient healing traditions, to corporate team-building programs. Polster and Polster (1973:42) describe how this process is experienced as chaos which disrupts the previous organisation and previously successful ways of coping. It is however, precisely this situation that "invites new solutions, new configurations and new viewpoints".

The experiential nature of the training caused this type of bonding to occur between each learner and our trainer. We propose that this bonding facilitated the empathy which is required for therapists to be able to truly understand the nature of the clients' lived world so that there is a sense of accompanying the clients on their chosen paths. It is out of this shared understanding that the therapist's guiding responses seem so attuned to the client's needs. We would argue that this entails a shift from therapist to servant-leader as described by Greenleaf (1991:24) where the therapist needs at all times to consider the ethical context of the interaction with the client.

\section{The here-and-now}

According to Gestalt Therapy, power is in the present since only the present exists and one can only change in the present (Perls, 1973:63). Gestalt Therapy recognises that the past plays a significant role in individual life and that every individual has a unique past. However, in Gestalt Therapy past and future concerns are addressed in the present (Polster \& Polster, 1973:7). The individual thus gives each experience, be it past, present or future (experienced as anxiety) a new context in the present.

Perls (1973:64) maintains that the now encompasses all that exists for the individual. Remembering the past and anticipating the future are experiences sited in the present (Perls, 1969:92). Neurological studies have revealed that the storage and retrieval of memories is a complex process during which memories may be reworked or reconstructed, either fully or partially (Damasio, 2000:228). If neural structures can be, and are, modified by subsequent experiences, it is evident that memory cannot be a facsimile for an event, but is rather a record of the person's subjective experience of that event. Some memories also may not be restored to consciousness again, remaining 'stored' but not utilised. It is hypothesised that they may be involved in the retrieval of other memories, either as fact or emotional state. In these cases the connections may indeed exist, and accurately reflect a past event, or the re-working of it, but at an unconscious level which could be considered a covert memory store.

Hence the phenomenon of perception acts as a ground within which meaning is proposed or imagined, is worked with, and is accepted. Merleau-Ponty (Bruzina, 1970:58) has termed this field a stratum of "operating intentionality" and its revelation circumvents the question of objectivity as it is pre-objective and pre-personal. This provides a foundation for the very being of the person for meaning genesis. In rational knowing, the world is understood through analytical and logical thinking and the validity of this knowing is dependent upon its consistency in logical and rational terms. Metaphorical knowing however is sited in symbolic processes through which the world is represented and understood and its validity is based on whether these metaphors can encompass other spheres of experience (Lyddon \& Bradford, 1995:5).

\section{Training as an instance of research}

Van Manen (2002:6) addresses the question of the value of phenomenological reflection as research. In attempt- 
ing to portray lived experience, it cannot be said that the reflection will yield either absolute truth or objective observation, but rather a palimpsest of the meaning of the experience for the person. This is indeed the case for us in writing this paper, which attempts to capture something of this personal meaning for us who have experienced this training. From this perspective then, it is evident that such insights have limitations as no interpretation is ever complete or final, but is rather a process of continuous becoming. While life is lived and experienced in the present moment, the study of the lived experience can only occur retrospectively through memory and language. It is a fundamental tenet of hermeneutic phenomenology that people seek to create meaning of their experience from the response to be found within human consciousness. While phenomenological reflection requires for a certain setting aside of self, as in 'bracketing', this does not mean that the contextual issues such as the social, historical, and biographical aspects of the self are cast off. Moreover, the value of phenomenological inquiry lies in the sphere of its capacity to increase the practitioner's perceptiveness and tactfulness so that "the reflective experiences may bring about an intensified awareness of phenomena that sometimes seem profound" (Van Manen, 2002:8). From such profound awareness, it is possible for existential questions to be addressed.

Indeed this script is derived from the accounts of our experience. As noted by Kahn (2000:59), any script, being removed in time from the experience, is also "symbolic and distanced from the experiences of interest in order to allow hermeneutic interpretation". At the outset it was constructed by the each person individually for the group to make sense of the event, as a commentary on what had been experienced. Our meetings to discuss the training experience could be compared to a miner panning for gold nuggets with our collective experience as the source of meaning. This occurred during a number of conversations in which there was a reciprocal exchange of information following on the spontaneous emergence of 'leads'.

\section{Into the future: the application of the train- ing for us as therapists}

The process of reflecting on our experience gave it meaning initially through the distillation of patterns and themes, and subsequently through the creation of an interwoven structure of connected experiences. Thus, as researchers we became a part of the process through our personal connection with the phenomenon. This authentic desire to fully understand each other's lifeworld, changed us as researchers, because such depth of understanding inspired a mutual sense of compassion and caring and in this diverged significantly from positivist research methods. In addition, the experience of Gestalt therapy has inspired in us an attitude of attentiveness and respect for the dignity of the client born from a sense of wonder for the uniqueness of each person's experience.

For us the process of Gestalt therapy, speaks of the inner essence of humanity, and this entails not guiding or interpreting, but rather journeying as fellow travellers within a context of intersubjective reality generating meaning for both therapist and client. From this emerges a moral and principled foundation that governs a commitment to an ethical existence and therapeutic practice, suffusing it like veining in marble. As a final observation, as Capra (1997:257) has indicated, the words for soul or spirit and breath (of life) are the same in many ancient languages. This has a certain resonance for us, as the experience of Gestalt therapy provided an element of spiritual sustenance which has animated us, facilitating the transcendence of difficulties through an over-arching sense of the meaningfulness of the experience.

\section{CONCLUSION}

It may be noted that there is a certain lack of standardisation in the finished product, as each gestalt and therefore all practitioners' Gestalt Therapy will be a unique result of their own backgrounds, beliefs and interactions. The process of transformation, and even transcendence as discussed in this article, is at best an intangible term and decidedly difficult to measure. In the third instance it must be mentioned, and is certainly evident from the above discussion, that such training requires a deep commitment from the participants and a safety of training environment, which may not be equally easy to achieve or attain for all groups of trainees.

However, the process of Gestalt Therapy and training is deeply respectful of all individuals' experiences of their own gestalt while acknowledging that this unique 
gestalt contributes richly to a greater gestalt from which the group of trainees or even the client-therapist relationship can benefit immensely. This brings the conclusion that as South Africans we are indeed creating a unique Gestalt Therapy, essentially different from that of Perls. This is self-evident in light of our unique political past hallmarked by apartheid and youth protests, our multi-cultured and multi-lingual society as well as our situatedness as part of a larger developing continent. The goal of this article is therefore to introduce Gestalt Therapy and training as a respectful path of embracing our differences and finding a greater unified gestalt produced from this uniqueness. This article also then mirrors the greater gestalt described by the group of trainees consisting of each unique individual gestalt.

We, as learners, discovered that the goals of Gestalt therapy are not accomplished in exercising a strategy. We found that it is unhelpful to run ahead of the process and attempt to facilitate healing by following the progressive steps of a pre-conceived strategy. Rather, by entering the lived experiences of the client's world in the here-and-now, by the unconscious and mysterious process of two souls connecting, the therapist is able to lead 'from two steps behind', as it were. Gestalt therapy is an experiential therapy rather than an interpretive one with the emphasis on understanding the 'now'. For genuine contact to take place, the therapist must be present as a human being and be fully available in the lived interaction between self and client, surrendering to the dialogue, practising inclusion and experiencing full mutuality with the client. In this way, we experienced a transition from learner to actual therapist-client-observer-researcher. Every instance of Gestalt therapy was unique as each interaction is the joining of two souls which informs the therapeutic encounter. Thus each was an occasion where we took what we had and what we found to be within us.

\section{REFERENCES}

BANKART, CP 1997: Talking curves: A history of western and Eastern psycho-therapies. Pacific: Brooks/Cole.

BECVAR, DS \& BECVAR, RJ 2000: Family therapy. A systemic integration. Boston: Allyn \& Bacon.

BOWLBY, J 1988: A secure base: Parent child attachment and healthy human development. New York: Basic Books.

BRUZINA, R 1970: Logos and Eidos: The concepts in Phenomenology. Paris: Mouton.
BUBER, M 1967: A believing humanism. New York: Simon \& Schuster.

BUBER, M 1970: I and thou. Edinburgh: T \& T Clark.

BUCKLEY, B 2003: Revolution and evolution. American Journal of Psychotherapy, 57(1):1-17.

CAPRA, F 1997: The web of life. London: Harper \& Collins.

CHURCHLAND, PS 1986: Neurophilosophy: Toward a unified science of the mind-brain. Massachusetts: MIT

DAMASIO, A 2000: The feeling of what happens: Body, emotion and the making of consciousness. London: Vintage.

FAGAN, J 1972: The tasks of the therapist. (In: FAGAN, J \& SHEPERD, IL eds. 1972: Gestalt therapy now. London: Penguin). FREEMAN, WJ 1996: Happiness doesn't come in bottles. Journal of Consciousness Studies, 4:67-71.

GERGEN, K 1991: The saturated self. New York: Basic Books. GREENLEAF, RK 1991: Servant leadership: A journey into the nature of legitimate power and greatness. New Jersey: Paulist . HILLMAN, J 1976: Re-visioning psychology. New York: Harper \& Row .

KAHN, D.L. 2000: How to conduct research. (In: Cohen, ZM; Kahn, DL \& Steeves, RH 2000: Hermeneutic phenomenological research: A practical guide for nurse researchers. Thousand Oaks: Sage, pp.57-70.)

KAUFMANN, W. 1970: I and You: A prologue. (In: BUBER, M 1970: I and thou. Edinburgh: T \& T Clark.)

LAZAR, R 2000: Presentness: An intersubjective dimension of the therapeutic act. American Journal of Psychotherapy, 84(3):340-364.

LYDDON, WJ \& BRADFORD, E 1995: Philosophical commitments and therapy approach preferences among psychotherapy trainees. Journal of Theoretical and Philosophical psychology, 15(1):1-15.

PERLS, FS 1969: Ego, hunger and aggression. New York: Vintage Books.

PERLS, FS 1973: The Gestalt approach and eyewitness to therapy. Ben Lamond: Bantam Books.

PERLS, FS; HEFFERLINE, RE \& GOODMAN, P 1951: Introjection. (In: Perls, F 1951: Gestalt Therapy: Excitement and growth in the human personality. New York: Real People Press.)

PERT, C 1997: Molecules of emotion: Why you feel the way you feel. Glasgow: Simon \& Schuster.

POLSTER, E \& POLSTER, M 1973: Gestalt therapy integration: Contours of theory and practice. New York: Brunner/Mazel.

PROCHASKA, JO \& NORCROSS, JC 1999: Systems of psychotherapy: A transtheoretical analysis. Pacific Grove: Brooks/Cole. SINAY, S 1997: Gestalt for beginners. New York: Writers \& Readers.

TERRELL, CJ \& LYDDON, WJ 1996: Narrative and psychotherapy. Journal of Constructivist Psychology, 9(1): 27-44. 
VAN MANEN, M 2002: Writing in the dark: Phenomenological stud-

ies in interpretive inquiry. Ontario: Althouse. 